American Journal of Agricultural and Biological Sciences 6 (1): 148-154, 2011

ISSN 1557-4989

(C) 2010 Science Publications

\title{
Study on Nitrogen Concentration of Corn Hybrids
}

\author{
${ }^{1}$ Pravin Gautam, ${ }^{1,2}$ Dawn Gustafson and ${ }^{1}$ Zeno Wicks III \\ ${ }^{1}$ Department of Plant Science, South Dakota State University, Brookings, SD 57007 \\ ${ }^{2}$ Pannar Seed Inc., 40329 US Highway 14 East, Huron, SD 57350
}

\begin{abstract}
Problem statement: Though Nitrogen $(\mathrm{N})$ is vital in different physiological and developmental processes in plants and animals, it poses several environmental, nutritional and health problems, if present in excess amounts. Reduction in excess input of $\mathrm{N}$ into the soil, thereby reducing environmental problems and consequently nutritional and health problems, can be achieved by balancing their concentration in animal feed. Therefore, this research aims to quantify the $\mathrm{N}$ concentrations in commercially adapted corn hybrids in South Dakota and to determine if selection can be carried out for this trait to develop useful inbred lines; to determine the effect of planting densities on $\mathrm{N}$ concentrations and Dry Matter (DM) yields. Approach: Ten hybrids were planted in randomized complete block design with three replications and two population densities at three different locations in South Dakota. Whole plants sampled at silage harvesting stage were analyzed for $\mathrm{N}$ and nitrate concentration and dry matter yield. Results: Hybrid differences based on pooled variance for percent nitrogen were significant. There was no difference in mean $\mathrm{N}$ concentration between two planting populations. DM yields were highly dependent on hybrids' genetics but were altered by environments. Hybrids 2D601, N67-T4, N70-T9 and DKC54-51 were the better in terms of overall performance. On an average, they had $\mathrm{N}$, nitrate concentrations and $\mathrm{N}$ uptake on lower range; DM yield and plant stand percentage in the higher range. Hybrids 35y54, LG2489Bt and 34n43 were on the higher range of $\mathrm{N}$ and nitrate concentrations and $\mathrm{N}$ uptake, variable in DM yields, basically towards lower range. Conclusion: Our results show that hybrids are genetically variable in terms of $\mathrm{N}$ concentration. Therefore, it is possible to carryout selection based on these parameters. However, effect of environments should be considered while establishing a selection program. Further, selection based on $\mathrm{N}$ concentration can be carried out without giving up DM yields. It is suggested to include more and diversified germplasm for further study.
\end{abstract}

Key words: Nitrogen concentration, corn hybrids, dry matter yield, nitrate concentration

\section{INTRODUCTION}

Nitrogen (N) is crucial nutrient elements to both plants and animals for their growth and development (Barber et al., 1967; Chevalier and Scharader, 1977; Gallais and Hirel, 2004; Hay et al., 1953; Jones, 1985). However, if it is present in excess amounts either in plants or animal, which in turn will go to the soil and have an adverse impact to the environment causing eutrophication of water bodies (Johnson et al., 2007; Wardyn, 2002). It is reported that application of cattle manure results in increased nitrate leaching compared to chemical fertilizers (Mohammed et al., 2009). In addition, it affects animal and human health. Concentration of $\mathrm{N}$ in corn plants plays a crucial role in intake of nutrients by animals. Several studies have been done looking for the concentration of $\mathrm{N}$ in corn especially in seeds (Beauchamp et al., 1976; Chevalier and Schrader; 1977; Pollmer et al., 1979; Wardyn, 2002). However, there is no study on the concentrations of $\mathrm{N}$ on a whole plant basis for the use of silage.

The ethanol industry is in the midst of a considerable expansion period in South Dakota and the surrounding states (Tjardes and Wright, 2010). With the increase of ethanol processing plants, there will be change in feeding habit of animals with increased amounts of a highly nutritive feed product, Distillers Grain (DG). Therefore, it is imperative to manage the intake of $\mathrm{N}$ by animals through silage.

Average planting rates for corn have been significantly increased in the past decades. Planting density is approaching 74,131 seeds $\mathrm{ha}^{-1}$ (30,000 seeds per acre) in some northern Corn Belt states (Paszkiewicz and Butzen, 2003). Several researchers studied the planting density and its effect on grain and silage yield; and silage quality parameters (Cusicanqui 
and Lauer, 1999; Roth et al., 2000; Schroeder, 2004). However, the study of planting density in terms of $\mathrm{N}$ concentrations in the whole plants is lacking.

Therefore, the general objective of this research is to find out which hybrids have low and high concentration of $\mathrm{N}$ and to find the line which can be used for further breeding of low-N corn. However, the specific objectives of this research are; to quantify the whole plant $\mathrm{N}$ concentration in commercially adapted corn hybrids in South Dakota; to detect variance factors for $\mathrm{N}$ concentrations; to identify the relationship between $\mathrm{N}$ concentration and DM yield; to identify the effect of plant population in $\mathrm{N}$ concentration and $\mathrm{DM}$ yield; and to determine whether selection of corn varieties can be carried out for further development of inbred lines based on whole plant $\mathrm{N}$ concentration.

\section{MATERIALS AND METHODS}

Generally, a corn hybrid that is a high grain yielder will be a top silage producer. Many special silage hybrids are simply tall growing, long season hybrids and may not yield as much nutrients as top grain yielding hybrids (Wheaton et al., 1993 and Roth and Undersander, 1995). Considering these facts, financial constraints and on the basis of consultation with seed companies, 10 hybrids were selected for the experiment. Hybrids used in the study, their relative maturity, recommended planting density, hybrid type and the seed companies which released them are listed in Table 1.

As multi-location and multi-year analysis increases reliability of the study, the experiment was conducted at the SDSU Agricultural Experimentation Stations at three locations, namely; Brookings Agricultural Research Station, Brookings (BKG), South East Research Station, Beresford (BSF) and North East Research Station at Watertown (WTN) in 2004 and 2005. Soil at all locations was of medium textured. Soil type at Beresford was Egan-Clarno-Trent Complex with
0-6 percent slopes. Brookings had Vienna-Brookings Complex with 1-6 percent slopes (NCRS, 2006). Similarly, soil type at Watertown was Brookings Silty Clay Loam with 0-3 percent slopes. Soil $\mathrm{pH}$ was approximately in the range required for the efficient uptake of $\mathrm{N}$ and P. Beresford had a $\mathrm{pH}$ of 5.9 in both years. Brookings had 6.4 and 7 soil pH in 2004 and 2005, respectively. Watertown had 6 and 5.7 soil pH in 2004 and 2005, respectively.

All locations were planted in conventionally tilled, rain-fed systems. Planting dates were determined when air temperatures averaged near $12-15^{0} \mathrm{C}$ (Shaw, 1988). Further, planting was synchronized with the surrounding corn fields' planting dates.

The study was conducted using a Randomized Completely Block design with three replications. Each variety was planted in two rows of 40 seeds per row (73,398 plants ha $\left.{ }^{-1}\right)$ for low population density and 48 seeds per row $\left(93,910\right.$ plants $\left.\mathrm{ha}^{-1}\right)$ for high population density. Length of a row was $6.08 \mathrm{~m}$ with row spacing of $0.762 \mathrm{~m}$.

The proper moisture content of corn at harvest for silage is between $60-70 \%$. This is during the stage when milk line is $2 / 3$ rd $-1 / 3 r d$ down the kernel (Roth and Undersander, 1995; Phillips, 2005).

The plants were hand harvested by sickle when the milk line was 1/2nd-2/3rd down the kernel. Further, the harvesting time was synchronized with the surrounding area farmers' silage fields. Ten plants, five from each row, were randomly harvested from each hybrid at ground level. The harvested ten plants of each hybrid were combined and weighed in the field for wet weight. Samples were then cut and put into a sac in order to avoid loss of any plants parts. Plants were dried in a forced-air dryer at $32.2^{\circ} \mathrm{C}$ for $20-25$ days at which time a dry weight measurement was taken. Dry matter yield was calculated based on wet weight and dry weight and expressed in $\mathrm{Mg} \mathrm{ha}^{-1}$. Plants were counted at the time of harvesting for plant stand calculations.

Table 1: Hybrids, their type, seed company which released them, recommended planting density, Relative Maturities (RM) days, type and their ranks observed in terms of plant stand percentage, Dry Matter (DM) yield, nitrogen (N) concentration and Nitrate concentration

\begin{tabular}{|c|c|c|c|c|c|c|c|c|}
\hline \multirow[b]{2}{*}{ Hybrids } & \multirow[b]{2}{*}{ Type } & \multirow[b]{2}{*}{ Seed company } & \multirow[b]{2}{*}{$\begin{array}{l}\text { Recommended } \\
\text { planting density }\end{array}$} & \multirow[b]{2}{*}{$\begin{array}{l}\text { Relative } \\
\text { maturity (RM) }\end{array}$} & \multicolumn{4}{|c|}{ Ranks* } \\
\hline & & & & & Stand & DM yield & $\mathrm{N}$ conc. & Nitrate \\
\hline 2D601 & Silage & Mycogen & Medium low - medium & 106 & 7 & 9 & 8 & 6 \\
\hline 2R570 & Grain & Mycogen & High & 104 & 5 & 5 & 3 & 4 \\
\hline $34 n 43$ & Grain & Pioneer & 34-36,000ppa & 110 & 9 & 8 & 4 & 7 \\
\hline $35 y 54$ & Gain & Pioneer & $34-36,000 \mathrm{ppa}$ & 105 & 10 & 3 & 1 & 5 \\
\hline DKC50-18 & Grain & DEKALB & Medium-high & 100 & 2 & 1 & 10 & 9 \\
\hline DKC54-51 & Grain & DEKALB & Medium-high & 104 & 1 & 4 & 9 & 1 \\
\hline LG2463Bt & Silage & LG seeds & 26-32,000ppa & $\begin{array}{r}104 \\
96\end{array}$ & $\begin{array}{l}1 \\
3\end{array}$ & $\begin{array}{l}4 \\
2\end{array}$ & 7 & 3 \\
\hline LG2489Bt & Silage & LG seeds & 28-33,000ppa & 100 & 8 & 10 & 2 & 10 \\
\hline N67-T4 & Dual & Syngenta & 22-30,000ppa & 103 & 4 & 6 & 5 & 8 \\
\hline N70-T9 & Grain & Syngenta & $22-30,000$ ppa & 112 & 6 & 7 & 6 & 2 \\
\hline
\end{tabular}

* Rank 1 has the highest value and rank 10 has the lowest value of the measured parameters 
Dried plants were then chopped in a chopper and ground to powder, passing through a $1 \mathrm{~mm}$ sieve, from which a sub-sample was taken from each grounded sample. Total $\mathrm{N}$ and nitrate concentration in the samples were analyzed using the nutrient analysis method used in SDSU Soil and Plant Analysis Laboratory; Kjeldahl nitrogen analysis method for total $\mathrm{N}$ analysis (Barber et al., 1967). Nitrogen and nitrate concentrations (in percentage) obtained from lab analysis was used to obtain $\mathrm{N}$ and nitrate concentrations $\left(\mathrm{gm} \mathrm{kg}^{-1} \mathrm{DM}^{-1}\right.$ ) in whole plants, in terms of dry matter, as by Pollmer et al. (1979). The $\mathrm{N}$ concentration of whole plants when expressed in terms of area was termed as N uptake (Pollmer et al., 1979; Gallais and Hirel, 2004) and expressed in $\mathrm{Mg} \mathrm{ha}^{-1}$.

Data from the lab analyses and the field were analyzed by using SAS Ver.9 program. Analysis Of Variance (ANOVA) procedures were run over all locations for nitrogen, dry matter yield, plant stand and $\mathrm{N}$ uptake. Test of homogeneity of error variance was done as per Gomez and Gomez (1984) before doing combined analyses of both years. Mean separation was done using Least Significance Difference (LSD) test. Regression analysis was run for stability analysis of hybrids at each density and Pearson's correlation coefficient was calculated to find out the relatedness of the variables.

\section{RESULTS}

Nitrogen concentration was significantly different among hybrids $(P=0.0073)$ and among plants grown at different environments $(\mathrm{P}<0.0001)$ in the combined 2004-2005 analysis (Table 2). The results show that there might be possible density treatment effects ( $\mathrm{P}=$ 0.0976). Environment BSF05 and BSF04 had the highest mean and BKG04 and BKG05 had the lowest mean $\mathrm{N}$ concentrations (Table 3 ).

Figure 1 depicts the mean $\mathrm{N}$ concentration, pooled over hybrids, at each environment and each planting density when plotted against the environmental mean $\mathrm{N}$ concentration. Though the regressions mean square were highly significant, the t-test showed that the slopes are not significantly different $\left(\mathrm{P}=0.0968, \mathrm{t}_{0.05}=-1.88\right)$, indicating that the rate of increase in hybrids' $\mathrm{N}$ concentrations in both the planting densities are not different when the environmental mean $\mathrm{N}$ concentrations is increased.

None of the variables had significant effect on nitrate concentrations except environments $(\mathrm{P}<0.0001$, data not shown). BSF05 had the highest nitrate concentration and BKG05 had the lowest concentration (Table 3). There were no significant differences in

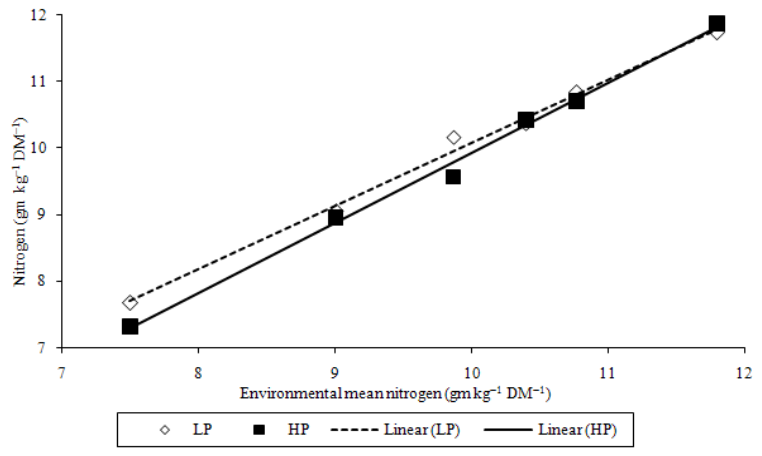

Fig. 1: Stability of nitrogen (N) concentration of corn hybrids in low planting density (LP) and high planting density (HP) across six environments, pooled over hybrids

nitrate concentration within the same location over years except at BSF. Therefore, it can be assumed that the nitrate concentration depends on an environmental factor other than the weather, possibly N. Relative maturity days was not significantly correlated with $\mathrm{N}$ concentration (Table 4).

The effect of hybrids was highly significantly different $(\mathrm{P}<0.0001)$ for plant stand percent When the combined analysis of variance was done for 2004 and 2005 (Table 2). Similarly, effects of environment and density were significant at the $5 \%$ level of significance. The mean plant stand percent of high density was 94.02 percent and that of low density, 95.18 percent, with an LSD(0.05) value of 0.987 percent. In terms of hybrids, DKC54-51 (104 RM days) was the hybrid with the highest and 35y54 (105 RM days) was the hybrid with the lowest plant stand percent (Table 1).

Variation in dry matter yields was highly significant due to environmental $(\mathrm{P}<0.0001)$ and density treatments $(\mathrm{P}<0.0001)$ in the combined analysis of 2004 and 2005 (Table 2). The interaction of environment by hybrids was highly significant $(\mathrm{P}=$ 0.0002). Performances of each hybrid were significantly different across environments. However, dry matter yield was significantly different between hybrids in BKG05 at the 0.05 probability level and in BSF05 at the 0.01 probabilities level but was nonsignificant at WTN. Mean dry matter yields across environment were significantly highest at BSF05 and significantly lowest at BKG04 (Table 3). High planting densities had a mean dry matter yield of $16 \mathrm{Mg} \mathrm{ha}^{-1}$ and low planting densities had a mean dry matter yield of $14.1 \mathrm{Mg} \mathrm{ha}^{-1}$, with a critical $\operatorname{LSD}_{(0.05)}$ value of $0.34 \mathrm{Mg}$ $\mathrm{ha}^{-1}$. The correlation between DM yield and RM days was non-significant (Table 4). 
Am. J. Agri. \& Biol. Sci., 6 (1): 148-154, 2011

Table 2: Combined analysis of variance of plant stand (\%), Dry Matter (DM) yield, Nitrogen (N) concentration, and Nitrogen (N) uptake in the experiment conducted during 2004 and 2005

\begin{tabular}{|c|c|c|c|c|c|}
\hline Sources of variation & DF & $\begin{array}{l}\text { Plant stand } \\
\text { Mean square }\end{array}$ & $\begin{array}{l}\text { DM yield } \\
\text { Mean square }\end{array}$ & $\begin{array}{l}\mathrm{N} \text { concentration } \\
\text { Mean square }\end{array}$ & $\begin{array}{l}\text { N uptake } \\
\text { Mean square }\end{array}$ \\
\hline Environment (Env.) & 5 & $51.440^{*}$ & $671.365 * * *$ & $134.353 * * *$ & $142065.74 * * *$ \\
\hline Variety (Var.) & 9 & $237.303^{* * *}$ & $4.872^{\mathrm{NS}}$ & $2.296 * *$ & $768.331^{\mathrm{NS}}$ \\
\hline Density (Den.) & 1 & $119.601 *$ & $324.679 * * *$ & $2.450^{\mathrm{NS}}$ & $23723.534 * * *$ \\
\hline Env.*Var. & 45 & $24.861^{\mathrm{NS}}$ & $5.615^{* *}$ & $1.032^{\mathrm{NS}}$ & $744.484 *$ \\
\hline Env.*Den. & 5 & $21.076^{\mathrm{NS}}$ & $3.816^{\mathrm{NS}}$ & $1.101^{\mathrm{NS}}$ & $1481.3001^{* *}$ \\
\hline Var.*Den. & 9 & $12.233^{\mathrm{NS}}$ & $2.799^{\mathrm{NS}}$ & $0.514^{\mathrm{NS}}$ & $258.165^{\mathrm{NS}}$ \\
\hline Env.*Var.*Den. & 45 & $20.564^{\mathrm{NS}}$ & $2.369^{\mathrm{NS}}$ & $0.819^{\mathrm{NS}}$ & $393.662^{\text {NS }}$ \\
\hline Error & 228 & 22.563 & 2.68 & 0.885 & 485.501 \\
\hline CV (\%) & & 5.02 & 10.872 & 9.516 & 14.611 \\
\hline
\end{tabular}

${ }^{\mathrm{NS}}$ Non-significant

* Significant at $0.05 \%$ level of significance

** Significant at $0.01 \%$ level of significance

*** Significant at $0.0001 \%$ level of significance

Table 3: Mean dry matter (DM) yield, mean nitrogen $(\mathrm{N})$ and nitrate concentrations and their rankings at six environments, pooled over densities and hybrids

\begin{tabular}{llllll}
\hline Environments & $\begin{array}{l}\text { Mean DM yield } \\
\left(\mathrm{Mg} \mathrm{ha}^{-1}\right)\end{array}$ & Rank & $\begin{array}{l}\text { Mean N concentrations } \\
\left(\mathrm{gm} \mathrm{kg} \mathrm{DM}^{-1}\right)\end{array}$ & $\begin{array}{l}\text { Rank } \\
\left(\mathrm{gm} \mathrm{kg}^{-1} \mathrm{DM}^{-1}\right)\end{array}$ \\
\hline BSF04 & $21.211 \mathrm{a} \dagger$ & 1 & $10.767 \mathrm{~b} \dagger$ & 2 & $0.894 \mathrm{~b}$ \\
BKG05 & $14.117 \mathrm{c}$ & 3 & $7.495 \mathrm{f}$ & 6 & $0.053 \mathrm{~d}$ \\
BKG04 & $11.505 \mathrm{e}$ & 5 & $9.003 \mathrm{e}$ & 5 & $0.092 \mathrm{~d}$ \\
BSF05 & $15.882 \mathrm{~b}$ & 2 & $11.800 \mathrm{a}$ & 1 & $4.335 \mathrm{a}$ \\
WTN05 & $14.457 \mathrm{c}$ & 3 & $9.867 \mathrm{~d}$ & 4 & $0.495 \mathrm{c}$ \\
WTN04 & $13.176 \mathrm{~d}$ & 4 & $10.397 \mathrm{c}$ & 3 & $0.490 \mathrm{c}$ \\
LSD $_{(0.05)}$ & 0.589 & & 0.338 & & 3 \\
\hline
\end{tabular}

$\dagger$ : Means with same lowercase letters within a column are not significantly different

Table 4: Pearson correlation between Nitrogen (N) concentration, nitrate concentration, Dry Matter (DM) yield, Nitrogen (N) uptake and Relative Maturity (RM)

\begin{tabular}{|c|c|c|c|c|c|}
\hline & N conc. & Nitrate & DM yield & $\mathrm{N}$ uptake & RM \\
\hline N conc. & & $\begin{array}{l}0.47205 \\
(<0.0001)^{*}\end{array}$ & $\begin{array}{l}0.30841 \\
(<0.0001)\end{array}$ & $\begin{array}{l}0.70069 \\
(<0.0001)\end{array}$ & $\begin{array}{l}0.02306 \\
(0.6628)\end{array}$ \\
\hline Nitrate & & & $\begin{array}{l}0.2595 \\
(<0.0001)\end{array}$ & $\begin{array}{l}0.41834 \\
(<0.0001)\end{array}$ & $\begin{array}{l}0.01696 \\
(0.7485)\end{array}$ \\
\hline DM yield & & & & $\begin{array}{l}0.88882 \\
(<0.0001)\end{array}$ & $\begin{array}{l}-0.03951 \\
(0.4548)\end{array}$ \\
\hline $\mathrm{N}$ uptake & & & & & $\begin{array}{l}-0.02497 \\
(0.6368)\end{array}$ \\
\hline
\end{tabular}

* Values in parenthesis indicate $\mathrm{P}$ value

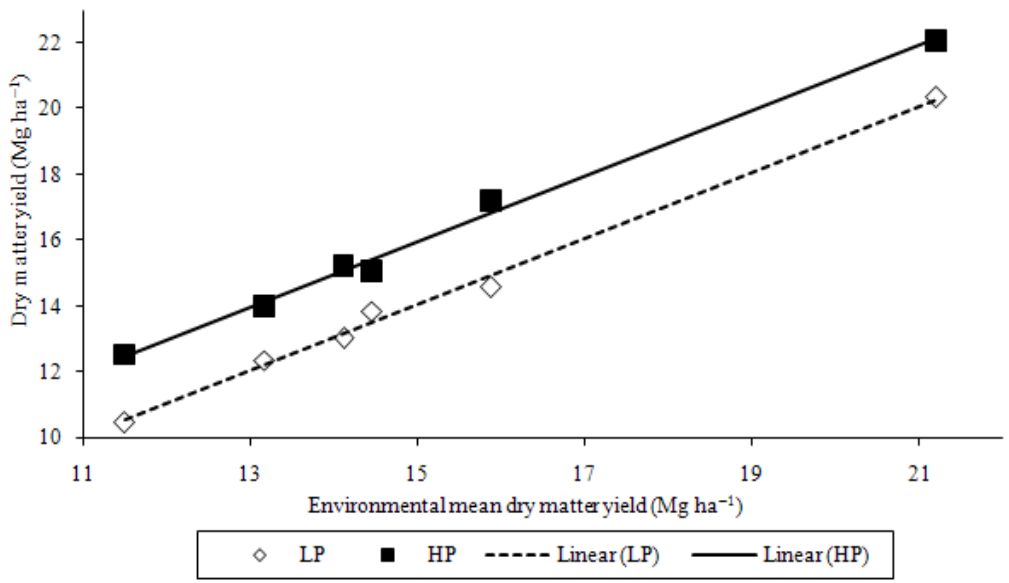

Fig. 2: Stability of dry matter (DM) yield of corn hybrids in low planting density (LP) and high planting density (HP) across six environments, pooled over hybrids 
Am. J. Agri. \& Biol. Sci., 6 (1): 148-154, 2011



Fig. 3: Stability of Dry Matter (DM) yield of corn hybrids in low planting density (LP) and high planting density (HP) across six environments, pooled over hybrids

Linear regression analysis of 2004-2005 (Fig. 2) shows the stability of dry matter yield of two different planting densities across ten hybrids and six environments. The high population densities show a higher yield over low populations across all environments. Though the linear regression analysis was highly significant for both planting densities, the t-test was not significant for the comparison of slopes indicating there is no density by environment interaction. Difference of mean dry matter yields over two planting densities was significantly different. Dry matter yield was increased by 13.46 percent when the planting density was increased from 73,398-93,910 plants ha ${ }^{-1}$.

Variations in $\mathrm{N}$ uptake were highly significant due to environments $(\mathrm{P}<0.0001)$ and the density treatments $(\mathrm{P}<0.0001)$ in the combined analysis of years 2004 and 2005 (Table 2). Similarly, the interactions of environment by hybrids and environment by densities were significant at the 0.05 level of probability. Uptake of $\mathrm{N}$ was significantly different between hybrids only at the BSF05 environment. But the performances of each hybrid were significantly different across environments. Similarly, each density treatment had a significant difference in $\mathrm{N}$ uptake across environments. However, the $\mathrm{N}$ uptake was significantly different between density treatments only in BSF05. At high planting densities the mean $\mathrm{N}$ uptake was $158.92 \mathrm{~kg} \mathrm{ha}^{-1}$ and was significantly different from the low planting densities (142.684 $\mathrm{kg} \mathrm{ha}^{-1}$ ).

Figure 3 shows the stability of $\mathrm{N}$ uptake in two different planting densities across ten hybrids and six environments. High population densities show a higher $\mathrm{N}$ uptake compared to low populations across all environments. Though the linear regression analysis was highly significant for both planting densities, the ttest was not significant for the comparison of slopes $\left(\mathrm{t}_{0.05}=-1.01, \mathrm{P}=0.3409\right)$, indicating no interaction of densities and environments. The results do show, however, that there were significant differences in mean $\mathrm{N}$ uptake between the two planting densities.

\section{DISCUSSION}

A study on the effect of planting density on $\mathrm{N}$ concentrations and DM yield of ten corn hybrids adapted in South Dakota was conducted. Objectives of the study was to identify whether selection can be carried out for whole plant $\mathrm{N}$ concentration in addition to observe the effect of planting density on their concentrations and DM yields. Experiments were conducted at the three locations and over two years in eastern South Dakota.

Interaction between hybrids and panting density was non-significant for all parameters, suggesting that response of hybrids will be similar across planting densities.

Maturity days did not have impact on $\mathrm{N}$ concentrations. This suggests that the concentrations of $\mathrm{N}$ in corn hybrids are mainly based on its genetics and environments. Nitrate concentrations in plants were different only due to the environment effects. Concentration of nitrates in plants from location BKG were below toxicity levels and were safe to feed, as suggested by Department of Animal Science at Michigan State University $(<0.44 \%$, McFadden et al., 2007). At WTN environment, nitrate concentration was in the range where it should be limited to less than $50 \%$ of ration DM (0.44-0.88\%). Corn plants from BSF 
environment had highest nitrate concentration and it should be limited to $25 \%$ of ration DM and should not feed to pregnant cattle. Since, there were not any study involving whole corn plant for $\mathrm{N}$ and nitrate concentration, we couldn't directly compare out results with other studies.

Plant stand percentage at the time of harvest was basically dependent on the hybrid and the environment where it is grown. However, plant stand percentage tends to be lower in high density mainly due to competition of more number of plants for the same amount of available resources.

DM yield was also dependent on environments and plant populations. DM yield also differed based on the environment where it is grown. Our result of insignificant impact of hybrid genetics on DM yield agrees with the findings of Cusicanqui and Laurel (1999). However, The result contrast with the result obtained by Yilmaz et al. (2007), where thy reported difference in DM yield in different genotypes of corn. High density population had significantly more DM yield production than from plants in low density populations, this might be due to the higher number of plants per given area. This result agrees with Turgut and Acikgoz, (2005) where they reported higher DM yield in high plant density (above 85,000 plants ha ${ }^{1}$ ) compare to low plant density $\left(65,000\right.$ plants ha $\left.{ }^{-1}\right)$. The increase of $13.6 \%$ in DM yield in high population density compared to low plant density was 6\% higher than results obtained by Rutger and Crowder (1967) when plant density was increased from 50,000-88,000 plants ha ${ }^{-1}$. In contrary, a recent study by Carpici et al. (2010) do not agree with our result. Carpici et al. (2010) reported no significant increase in DM yield when plant density was increased from 60,000-100,000 plants ha ${ }^{-1}$ in Turkey.

$\mathrm{N}$ uptake by hybrids was significantly different in environments and plant populations. $\mathrm{N}$ uptake was significantly higher in high density populations across all environments. Uptake of $\mathrm{N}$ by hybrids in our experiment was higher than the uptake found by Sprague (1989) in corn stover $\left(62 \mathrm{~kg} \mathrm{ha}^{-1}\right)$ and grain uptake (129 $\left.\mathrm{kg} \mathrm{ha}^{-1}\right)$. Hybrids did not perform consistently in all environments for $\mathrm{N}$ uptake.

Hybrids 2D601, N67-T4, N70-T9 and DKC54-51 were better in terms of overall performance. On an average, they had $\mathrm{N}$ and nitrate concentrations, $\mathrm{N}$ uptake on lower range; DM yield and plant stand percentage in the higher range. Though 2D601 had the lowest stand percentage, it had the highest DM yields and $\mathrm{N}$ and nitrate concentrations in lower range. Hybrids 35y54, LG2489Bt and 34n43 were in the higher range of $\mathrm{N}$ and nitrate concentrations and $\mathrm{N}$ uptake. They were also variable in DM yields, basically towards lower range. While, the Pioneer brand seeds were worst in terms of high nutrient concentrations, low yields and low stand percentage, Syngenta and Mycogen seeds were advantageous in terms of all characters measured.

\section{CONCLUSION}

Based on the results, it seems that hybrids are variable in terms of $\mathrm{N}$ and nitrate concentrations. Therefore, it is possible to carryout selection based on these parameters. However, effect of environments should be considered while establishing selection programs, as $\mathrm{N}$ concentration of plants interact with environmental effects. Further, selection based on $\mathrm{N}$ concentrations can be carried out without giving up the DM yields. It is suggested to include more germplasm for further study.

\section{REFERENCES}

Barber, W. D., W. I. Thomas and D. E. Baker, 1967. Inheritance of relative phosphorus accumulation in corn (Zea mays L.). Crop Sci., 7: 104-107.

Beauchamp, E.G., L.W. Kannenberg and R.B. Hunter, 1976. Nitrogen accumulation and translocation in corn genotypes following silking. Agr. J., 68: 418-422.

Carpici, E.B., N. Cleik and G. Bayram, 2010. Yield and quality of forage maize as influenced by plant density and nitrogen rate. Turkish J. Field Crops, 15: $128-132$.

Chevalier, P. and L.E. Schrader, 1977. Genetic difference in nitrate absorption and partitioning of $\mathrm{N}$ among plant parts in maize. Crop Sci., 17: 897-901.

Cusicanqui, J.A. and J.G. Lauer, 1999. Plant density and hybrid influence on corn forage yield and quality. Agronomy J., 91: 911-915.

Gallais, A. and B. Hirel, 2004. An approach to the genetics of nitrogen use efficiency in maize. J. Exper. Botany, 55: 295-306. DOI: 10.1093/jxb/erh006

Gomez, K.A. and A.A. Gomez, 1984. Statistical Procedures for Agricultural Research. 2nd Edn., Wiley-Interscience, USA., ISBN-10: 0471870927, pp: 704.

Hay, R.E., E.B. Earley and E.E. Deturk, 1953. Concentration and translocation of nitrogen compounds in the corn plant (Zea mays) during grain development. Plant Physiol., 28: 606-621.

Johnson, P.T.J., J.M. Chase, K.L. Dosch, R.B. Hartson and J.A. Gross et al., 2007. Aquatic eutrophication promotes pathogenic infection in amphibians. PNAS, 104: 15781-15786. DOI: 10.1073/pnas.0707763104 
Jones, C.A., 1985. C4 Grasses and Cereals: Growth, Development and Stress Response. 1st Edn., John Wiley and Sons, Inc., New York, ISBN-10: 0471824097, pp: 419.

McFadden, M., H. Bucholtz and M. Allen, 2007. Harvesting Drought Stressed Corn for Silage. Michigan State University. https://www.msu.edu/ mdr/online/mcfadden1.html

Mohammed, T.A., M. Nooshin, M.J.M.M. Noor and A. Liaghat, 2009. Investigating the effect of three nitrate fertilizers on nitrate leaching under the root zone in clay loam soil. Am. J. Environ. Sci., 5: 387-392. DOI: 10.3844/ajessp.2009.387.392

Paszkiewicz, S. and S. Butzen, 2003. Corn Hybrid Response to Plant Population. Crop Insights, Pioneer Hi-bred International Inc. http://www.chappellseeds.ca/Information\%20for\% 20website/Corn\%20Agronomy/Corn\%20tech\%20s heets/Corn\%20Hybrid\%20Response\%20to\%20Pla nt\%20Population.pdf

Phillips, D.M.A., 2005. Harvesting Methods for Corn Silage Affect Performance. University of Kentucky. http://www.uky.edu/Ag/AnimalSciences/dairy/exte nsion/nut00019.pdf

Pollmer, W.G., D. Eberhard, D. Klein and B.S. Dhillon, 1979. Genetic control of nitrogen uptake and translocation in maize. Crop Sci., 19: 82-96.

Roth, G. and D. Undersander, 1995. Corn Silage Production, Management and Feeding. 1st Edn., Diane Pub Co., USA., ISBN-10: 0788178229, pp: 42.

Roth, G., M. Antle and R. Kyper, 2000. Hybrid, Plant Population and Row Spacing Effects on Corn Silage Performance in Pennsylvania. Penn State University. Report No No1. http://cornandsoybeans.psu.edu/pdfs/CMRR00-01.pdf
Rutger, J.N. and L.V. Crowder, 1967. Effect of population and row width on corn silage yields. Agron. J., 59: 475-476.

Schroeder, J.W., 2004. Corn Silage Management. NDSU Extension Service, North Dakota State University. Publication No. AS-1253. http://www.ext.nodak.edu/extpubs/ansci/dairy/as12 53w.htm

Shaw, R.H., 1988. Climate Requirement. In: Corn and Corn Improvement-Agronomy Monograph, Sprague, G.F. and J.W. Dudley (Eds.). Agronomy, pp: 609-638.

Sprague, G.F., 1989. Corn and Corn Improvement. $3^{\text {rd }}$ Edn., American Society of Agronomy-Crop Science Society of America-Soil Science Society of America, ISBN-10: 0891180990, pp: 699.

Tjardes, K. and C. Wright, 2010. Feeding Corn Distiller's Co-products to Beef Cattle. Extension Extra, ExEx 2036, South Dakota State University. http://www.extension.org/pages/Feeding_Corn_Dis tiller\%E2\%80\%99s_Co-Products_to_Beef_Cattle

Turgut, I. and E. Acikgoz, 2005. Alternate row spacing and plant density effects on forage and dry matter yield of maize hybrids (Zea mays L.). J. Agron. Cr. Sci., 91: 146-151.

Wheaton, H. N., F. Martz, F. Meinershagen and H. Sewell, 1993. Corn Silage. University of Missouri Extension. Publication No. G-4590. http://muextension.missouri.edu/explore/agguides/ crops/g04590.htm

Yilmaz, S. and I. Atis, 2007. Genotype and plant density effects on corn (Zea mays L.) forage yield. As. J. Plan. Sci. 6: 538-541. 